\title{
The Same, But Different: The Educational Affordances of Different Gaming Genres
}

\author{
Alex Frazer, David Argles, Gary Wills \\ University of Southampton, Southampton, UK \\ \{ajf06r,da,gbw\}@ecs.soton.ac.uk
}

\begin{abstract}
As research continues into the use of computer games for educational purposes, the differences between different gaming genres become increasingly more important. These differences, however, appear to have been largely overlooked by the academic community, potentially resulting in incomplete results when considered against computer gaming as a whole. This paper studies a selection of games from several different genres, assessing each one in its ability to fulfill a set of previously identified requirements for a good educational resource. The results of the investigation showed that there were indeed differences between the genres, allowing for some suggestions to be made regarding their use, as well as leaving room for some interesting future work.
\end{abstract}

\section{Introduction}

Research into educational computer games has become more prominent in recent years, with a number of important papers published from leading academic figures $[5,6,10]$. However, an oversight made by many authors (as pointed out by Squire [9, 11]), is the classification of different gaming genres - or rather the lack of it. The prominent papers in the field discuss the different affordances offered by computer and video games to education, as if all genres of game can offer them with equal success. As the world of computer gaming has evolved tremendously since its beginnings, the diverse characteristics of modern games suggest that this is not the case. To explore this idea, we present an investigation into a number of games, taken from four different genres, where we assess their effectiveness at satisfying certain affordances useful to education.

\subsection{Existing Research}

In his paper, "Changing The Game: When Video Games Enter the Classroom" [11], Squire discusses several potential benefits to education, offered by video games. While he himself uses the popular strategy game "Civilization III" as an example, he points out that it may not be the game for everyone, and that educators should expect different game-play experiences from games of different genres. However, as these different experiences are not discussed in further detail, a gap is left for our investigation.

Hogle [7] identifies several gaming genres, as well as some educational affordances offered by video games. However, the two are never mapped to one another, and the proposed affordances are presented in a genre agnostic fashion. As such, the paper offers no real elaboration on the inter-genre differences highlighted by Squire.

Amory et al. attempt to analyse the differences between gaming genres, but take a different approach to ours [1]. Taking one game from each of four genres ("strategy", "adventure", "simulation" and a firstperson shooter labeled as a "shoot-em-up"), a group of 19 users were asked to play the games, and evaluate how well they satisfy certain qualities. While the results show that there are differences between the gaming genres, there doesn't appear to be any sound rationale behind the selection of these qualities. In addition, only one game was taken from each of the chosen genres, failing to show how different games within a genre can still offer very different game-play experiences.

Fabricatore [3] suggests an "interactive cycle", consisting of "analytical capabilities", "strategic thinking", "psychomotor skills" and "enrichment of players' knowledge". Yet, for example, turn-based strategy games require negligible psychomotor skills, and classic, reaction-based "shoot-em-ups" are unlikely to enrich the player's knowledge base to any noticeable 
degree. The elements of the cycle are potentially valid, but not universally so.

Paras and Bizzocchi [8] discuss features of gaming, including "reflection", where the player considers their past in-game actions to inform their actions in the future. However, certain games - such as the kind of mini-games found prominently on the Web - have been shown to be too short to offer opportunity for reflection. So again, while the claim that games offer opportunities for reflection is potentially true, it will not be so in every case.

\section{Method}

In order to identify some of the differences between gaming genres, a set of genres had to be chosen, followed by a number of games from each one. The genres we selected are by no means exhaustive, but represent a large proportion of games available today, and are different enough from one another to warrant distinction.

The genres we selected were:

- "First-Person Shooter" (a popular, combat-heavy genre where the player views the game from the perspective of the main character),

- "RPG Adventure" (a hybrid genre focusing on character development and problem solving),

- "Puzzle" (where the player has to solve increasingly more intricate puzzles, usually relying on a single, core mechanism)

- "Strategy" (where resource management, planning and strategic deployment are the main player requirements).

Having selected three games from each genre, we played through them, paying special attention to identify features from our previously compiled requirements [4], detailing useful requirements for an educational game.

\section{Results}

Here, we discuss some of the more poignant features demonstrated by the games we investigated, followed by a table detailing the complete observations from all of the games and genres.

\subsection{First-Person Shooters}

The games chosen to represent this genre were:

- "Half Life 2" (A story-driven game, blending combat, exploration and physics-based puzzle solving)
- “Team Fortress 2" (A stylised, online team combat game, featuring nine very different roles)

- "Battlefield 2" (an online modern war game, with a strong focus on teamwork)

All three games allow players to talk amongst themselves using text or voice chat. Messages can be sent to all players in the game, or just to players on the user's team. In addition, Battlefield 2 distinguishes smaller groups of players, called "squads" and the opportunity for in-squad chat is also provided. In addition, the game identifies a separate role of the "commander", who has access to more complex troop communications. These different communication options could cater well to individual or group-based learning activities, with the "commander" role being useful for instructors wishing to join in the game.

New knowledge is presented in all three games, in different ways (non-player character interactions, documents within the game world, explicit text popups). An additional feature of Battlefield 2 allows players to flag enemy positions on the radar when they are encountered in-game. This type of presentation could be interesting, allowing learners to teach each other whenever they find something out, rather than relying on the directions of their instructor.

Both Half Life 2 and Team Fortress 2 offer tools for users to create game levels, affording the creation of ingame environments. However, this requires skills in scripting, 3D modeling and texture design, not to mention the game design skills required to create a balanced level. So whilst possible, it is not necessarily feasible.

Rewards are offered in two different ways. Half Life 2 focuses on in-game rewards - better weapons, vehicles, and access to new areas. The other two games focus more on external rewards - social standing, respect and acceptance into online "clans". In both instances, the key is their benefit to the player in playing the game. The more they play, the more rewards they receive, the better their game-play experience, the more they are motivated to continue.

\subsection{RPG/Adventure}

The three games chosen within this genre were:

- "Final Fantasy X" ("FFX", a Japanese, storydriven Role-playing game),

- "Grand Theft Auto III" ("GTA III", an actionadventure game set in a sprawling, modern city)

- "Oblivion" (a fantasy medieval fantasy RPG/adventure, focusing on exploration and nonplayer character interactions) 
Games within this genre often revolve around an epic quest, and as such, a great deal of new information is offered throughout. All three games use non-player character ("NPC") interaction to expose information. GTA III uses key characters within the storyline, where almost every character in the other two games has something to say. This provokes players to explore the game world to find information on their own.

The balance of difficulty within RPG games is often difficult, typically relying on the process of "grinding": allowing the player to fight against weak enemies, each yielding a low number of experience points ("XP"), for a long time, in order to raise the level of their character. Taken to an extreme, a player could spend even longer than usual attacking these weak enemies, until their own experience level was so high, that the rest of the game would be incredibly easy. Because of its tedious nature, "grinding" is seen as a very poor means to an end as far as enjoyable game-play is concerned. GTA III takes a different approach, avoiding the concept of XP altogether. Because of the game's free-roaming "sandbox" nature, the player is free to try out different things whenever they please. If they find themselves stuck on a particular element of a mission, they can take time out to practice that skill in their own time, returning to the mission once they feel comfortable with the game's demands.

Goal provision varies between games. GTA III and Oblivion both have "missions" or "quests", where explicit objectives are marked on a map, along with clear instructions on what they need to do when they get there. However, FFX is much more vague. The player will often know roughly where they are going, or who they are looking for, but will not know what they are supposed to do when they get there. This is usually done to maintain dramatic tension within the story, but can often leave the player confused as to exactly what they should be doing.

\subsection{Puzzle}

The games selected for this genre are:

- "Tetris" (the classic, block-sorting game),

- "Polarium" (a game for Nintendo's handheld "DS" console, where players draw paths on the touchscreen to flip tile colours, in order to match those surrounding them)

- "Puzzle Quest" (similar to popular online minigame, "Bejeweled", with an additional "RPG-lite" layer on top).

Puzzle games typically do not offer any new knowledge as the game progresses, and both Tetris and
Polarium qualify this. All information required to play the game is revealed in the game manual or a simple tutorial level, with no "surprises" occurring later on. The games' complexity comes from more intricate combinations of the basic principles, rather than the addition of new game-play mechanisms entirely. Puzzle Quest offers an additional story, although it is very tenuously linked to the puzzle elements of the game. The interesting part of its RPG aspect is the process of "leveling up", which grants the player new skills to be used in the game. Whilst the story could be detrimental in an educational setting (by creating too great a divide between the educational segment, and the game-play section), asking players to factor their new skills into the way they play could be an interesting way of reinforcing what they are learning.

Puzzle games are quite limited in several of the fields identified as important. The only post-game feedback they offer to an instructor is a kind of score (number of "lines" removed in Tetris and Polarium, number of XP in Puzzle Quest), making it impossible for the instructor to see how exactly the player achieved success. All three games rely on a fixed play area, with new blocks, jewels or lines added when required, making exploration impossible.

The promotion of immersion may not seem an obvious feature of puzzle games - they are typically 2D, incredibly stylised and minimal in both appearance and function. However, puzzle games are some of the most renowned for promoting "zone" play, where the player becomes lost in the game in a state of "flow" [2], working almost entirely on reflexes as they ignore external stimuli. Tetris and Polarium are more suited to foster this phenomenon. The hypnotic, constantly falling blocks, the trance-inducing music, and the constant focus on a single area of the screen all work well to keep the player engrossed in the game ahead of any external distractions. Puzzle Quest doesn't do this quite so well, as the story elements and skill-selection pane all distract from the main playing area. Engrossment in this game typically comes from a combination of the game's "leveling up" RPG element, as well as its central game-play mechanic.

\subsection{Strategy}

The three games chosen in this genre were:

- "SimCity" (a popular city development game),

- "Civilization IV" (an epic, turn-based game of expanding empires) 
- "Company of Heroes" (a real-time strategy ("RTS") game, focusing on infantry and tank squads of the second World War).

Because information is essential to developing a robust strategy, all three games demonstrate new knowledge to the player in useful ways. SimCity expresses new knowledge through the state of the city itself. A player can learn that a city needs a better water supply because its houses will fall into dereliction. They will learn the importance of better inter-city roads when migration between their city and others decreases. A panel of "advisors" is also on hand to offer additional information when required. Civilization IV is perhaps even more rigorously designed than SimCity, with a player action having a great number of ramifications in numerous other areas of the game. In addition, almost all game-play milestones (technological advances, completion of building projects, declarations of war) are accompanied by brief, informative cutscenes, again helping to provide a little additional information regarding important areas of the game.

Exploration is handled differently within the strategy genre. SimCity offers no real opportunity for exploration, as the whole map is visible (and empty) from the offset. However, both other games use exploration quite extensively as a game-play mechanism: Civilization on a large scale, exploring and conquering the world; Company of Heroes on a much smaller scale, infiltrating unknown enemy territory, using the terrain to your advantage as you encounter enemy troops and reclaim strategic points. In both cases, exploration into the unknown provokes tension, exciting the player as they progress through the game.

Similarly, difficulty balance occurs in different degrees. SimCity features a kind of implicit balance, whereby players are unable to access and build certain advanced structures before they have placed a number of key, basic ones. In doing this, the player demonstrates to the game that they are comfortable enough with the way basic structures work, such that they should understand how the advanced ones work. Civilization, on the other hand, doesn't really balance difficulty in-game. Once the player chooses a predetermined difficulty level at the start of play, they are bound to it for the rest of the game, and any signs of weakness are more likely to result in A.I. opponents wiping them out, than helping them out. Company of Heroes is even more punishing in this regard. As player's defending troops die, the enemy reclaims their outposts, and the player no longer earns resources from them. This means that they cannot afford to the replace the lost troops, allowing the enemy to easily move onto the next outpost to repeat the process. This negative feedback loop can be quite frustrating, quickly forcing the player into an inescapable situation without exposing it as such.

\section{Analysis}

Table 1 shows the complete results from the investigation, displaying the successes of each individual game. The first thing to notice is that the different genres do exhibit some differences in the affordances they offer.

The FPS games perform strongly in affording conversation, displaying new knowledge, encouraging exploration, immersing the player and offering rewards for success. However, they are poor at uniting resources and balancing difficulty, and are generally too fast-paced to work in blended learning scenarios.

The RPG/Adventure games lacked the FPS games' support for conversation, world creation and

Table 1 - The affordances offered by each inves tigated game

\begin{tabular}{|l|c|c|c|c|c|c|c|c|c|c|c|c|}
\hline & \multicolumn{3}{|c|}{$\begin{array}{c}\text { First-Person } \\
\text { Shooter }\end{array}$} & \multicolumn{3}{c|}{ RPG/Adventure } & \multicolumn{3}{c|}{ Puzzle } & \multicolumn{3}{c|}{ Strategy } \\
\cline { 2 - 15 } & $\mathbf{1}$ & $\mathbf{2}$ & $\mathbf{3}$ & $\mathbf{1}$ & $\mathbf{2}$ & $\mathbf{3}$ & $\mathbf{1}$ & $\mathbf{2}$ & $\mathbf{3}$ & $\mathbf{1}$ & $\mathbf{2}$ & $\mathbf{3}$ \\
\hline Conversation & $\mathrm{X}$ & $\mathrm{X}$ & $\mathrm{X}$ & & & & & & & & & \\
\hline New knowledge & $\mathrm{X}$ & $\mathrm{X}$ & $\mathrm{X}$ & $\mathrm{X}$ & $\mathrm{X}$ & $\mathrm{X}$ & & & $\mathrm{X}$ & $\mathrm{X}$ & $\mathrm{X}$ & $\mathrm{X}$ \\
\hline World creation & $\mathrm{X}$ & $\mathrm{X}$ & & & & & & $\mathrm{X}$ & & & & \\
\hline World exploration & $\mathrm{X}$ & $\mathrm{X}$ & $\mathrm{X}$ & $\mathrm{X}$ & $\mathrm{X}$ & $\mathrm{X}$ & & & & & $\mathrm{X}$ & $\mathrm{X}$ \\
\hline Useful feedback & & $\mathrm{X}$ & $\mathrm{X}$ & $\mathrm{X}$ & & $\mathrm{X}$ & & & & $\mathrm{X}$ & $\mathrm{X}$ & $\mathrm{X}$ \\
\hline Balance difficulty & & & & & & $\mathrm{X}$ & & & & $\mathrm{X}$ & & \\
\hline Clear goals & & $\mathrm{X}$ & $\mathrm{X}$ & & $\mathrm{X}$ & $\mathrm{X}$ & $\mathrm{X}$ & $\mathrm{X}$ & $\mathrm{X}$ & & & $\mathrm{X}$ \\
\hline
\end{tabular}




\begin{tabular}{|l|c|c|c|c|c|c|c|c|c|c|c|c|}
\hline Contextualisation & $\mathrm{X}$ & $\mathrm{X}$ & $\mathrm{X}$ & & & $\mathrm{X}$ & $\mathrm{X}$ & $\mathrm{X}$ & $\mathrm{X}$ & & & $\mathrm{X}$ \\
\hline Provoke curiosity & $\mathrm{X}$ & & & $\mathrm{X}$ & $\mathrm{X}$ & $\mathrm{X}$ & & & & & & \\
\hline Immersion & $\mathrm{X}$ & $\mathrm{X}$ & $\mathrm{X}$ & $\mathrm{X}$ & $\mathrm{X}$ & $\mathrm{X}$ & $\mathrm{X}$ & $\mathrm{X}$ & $\mathrm{X}$ & & & \\
\hline Offer rewards & $\mathrm{X}$ & $\mathrm{X}$ & $\mathrm{X}$ & $\mathrm{X}$ & $\mathrm{X}$ & $\mathrm{X}$ & & & $\mathrm{X}$ & $\mathrm{X}$ & $\mathrm{X}$ & $\mathrm{X}$ \\
\hline Unite resources & & & & $\mathrm{X}$ & $\mathrm{X}$ & $\mathrm{X}$ & & & & $\mathrm{X}$ & $\mathrm{X}$ & $\mathrm{X}$ \\
\hline Blended support & & & & & & & & & $\mathrm{X}$ & $\mathrm{X}$ & $\mathrm{X}$ & \\
\hline Full pedagogy & & & & & & & & & & & & \\
\hline Standards & $\mathrm{X}$ & $\mathrm{X}$ & & & & & & $\mathrm{X}$ & & & & \\
\hline
\end{tabular}

contextualization of information, but were much better at provoking curiosity and uniting different learning resources. This genre of game, therefore, may be better suited to a multimedia-heavy learning area, where learners need to explore a range of different learning resources in a self-motivated manner. In contrast, the FPS genre may be better at providing a setting where the environment itself is the learning resource to explore, with its opportunities for conversation allowing multiple users to be present in it at once.

The puzzle genre lacks many of the affordances offered by the previous two game types, but excels in its clear provision of goals, its opportunity to contextualize information well, and its deep immersive properties. This type of game may be better suited to explaining a single, important concept. It would allow the user to immerse him or herself in a working example of the concept, in order to thoroughly explore its intricacies without external distractions.

The strategy genre excels at providing new knowledge, uniting different resources and expressing information extremely clearly. It also often works well in blended learning situations, making it a strong candidate to enhance current, information-heavy teaching styles. The game could easily be played alongside a traditional, instructor-led session, with its efficiency at displaying rich, dense information being a strong replacement for the textbook. The detailed feedback offered to the user regarding their performance would also assist the instructor in assessing how well the learner had done.

\section{Conclusions and Future Work}

The results of the investigation suggest that different gaming genres do indeed offer different affordances that might be useful in educational contexts. As such, when considering the usefulness of "computer games" as educational tools, it is important to consider these differences, as we have seen that where one type of game fails, another may excel.
The genres chosen for this study are by no means exhaustive. There are others besides (simulators, sports games, the whole range of "casual" games), as well as within those chosen here (the Massively Multiplayer Online genre of RPG's deserves an entire section of its own, far beyond the scope of this paper). In addition, the games selected for the study are only a few out of hundreds in each genre, selected as being representative, rather than exhaustive. As such, plenty of room remains for further investigation in this area, broadening and deepening the community's understanding of the intricate differences between games, and the similarities between them.

\section{References}

[1] Amory, A. et al. (1999). "The use of computer games as an educational tool: identification of appropriate game types and game elements. In British Journal of Educational Technology, Vol. 30, No. 4, 1999.

[2] Csikszentmihalyi, M. (1997). "Flow and Education". In NAMTA Journal 1997, Volume 22, Issue 2.

[3] Fabricatore, C. (2000) "Learning and Videogames: An Unexploited Synergy". In proceedings of The International Conference of the Association for Educational Communications and Technology, 2000.

[4] Frazer, A., Argles, D. and Wills, G. (2007) "Is Less Actually More? The Usefulness Of Educational Minigames". In proceedings of The 7th IEEE International Conference on Advanced Learning Technologies, July 18-20, 2007.

[5] Gee, J. P. (2003) "What video games have to teach us about learning and literacy". In Computers in Entertainment, 2003. 
[6] Gee, J. P. (2004) "Learning by design: Games as learning machines". In Interactive Education Multimedia, No. 8, April 2004.

[7] Hogle, J. G. (1996). "Considering Games as Cognitive Tools: In Search of Effective Edutainment". Available online at: http://twinpinefarm.com/pdfs/games.pdf

[8] Paras, B. and Bizzocchi, J. (2005) "Game, Motivation and Effective Learning: An Integrated Model for Educational Game Design". In proceedings of DiGRA 2005 Conference: Changing Views - Worlds in Play.
[9] Squire, K. (2002) "Cultural Framing of Computer/Video Games”. In The International Journal of Computer Game Research, Vol. 2, Issue 1, July 2002.

[10] Squire, K. (2003) "Video games in education". In International Journal of Intelligent Simulations of Gaming, 2003.

[11] Squire, K. (2005). "Changing the game: What happens when video games enter the classroom”. In Innovate: Journal of Online Education, 2005. 